\title{
Generation of Free Radical Intermediates from Foreign Compounds by Neutrophil-derived Oxidants
}

B. Kalyanaraman and Peter G. Sohnle

National Biomedical ESR Center, Department of Radiology, and Infectious Diseases Section, Department of Medicine, The Medical College of Wisconsin, Milwaukee, Wisconsin 53226; and the Research Service, Veterans Administration Medical Center, Wood, Wisconsin 53193

\begin{abstract}
A large number of foreign compounds, including many drugs, industrial pollutants, and environmental chemicals, can be oxidized under appropriate conditions to potentially toxic free radical intermediates. We evaluated the ability of the oxidants produced by the neutrophil myeloperoxidase system to generate free radical intermediates from several such compounds. Sodium hypochlorite or hypochlorous acid produced by human peripheral blood neutrophils and trapped in the form of taurine chloramine were both found to be capable of producing free radicals from chlorpromazine, aminopyrine, and phenylhydrazine. These radical intermediates were demonstrated by visible light spectroscopy and by direct electron spin resonance (for the chlorpromazine and aminopyrine radicals) or by spintrapping (for the phenyl radical generated from phenylhydrazine). Stable oxidants produced by the neutrophils (i.e., those present in the supernatants of stimulated neutrophils in the absence of added taurine) also were found to be capable of generating free radical intermediates. The production of the oxidants and the ability of neutrophil supernatants to generate these radicals were almost completely eliminated by sodium azide, a myeloperoxidase inhibitor. We suggest that the oxidation by neutrophils of certain chemical compounds to potentially damaging electrophilic free radical forms may represent a new metabolic pathway for these substances and could be important in the processes of drug toxicity and chemical carcinogenesis.
\end{abstract}

\section{Introduction}

Many chemical compounds can be converted into free radical forms. The latter species are usually quite reactive and shortlived because they have a single unpaired electron in their outer orbital. Recently, evidence has accumulated to indicate that free radical intermediates may be important in the toxicity of a large number of substances (1-4). Free radicals can be formed by several mechanisms, including one-electron oxidation, one-electron reduction, homolytic cleavage of a $\mathrm{C}-\mathrm{H}$ bond, and in some cases by two-electron oxidation/reduction reactions. Enzyme-catalyzed oxidation also provides a mechanism by which free radical intermediates can be formed. Examples of this process include the generation of the chlorpromazine free radical cation $\left(\mathrm{CPZ} \cdot{ }^{+}\right)^{1}$ by hydrogen peroxide

Address reprint requests to Dr. Sohnle, Research Service/151, Veterans Administration Medical Center, Wood, WI 53193.

Received for publication 1 October 1984 and in revised form 3 January 1985.

1. Abbreviations used in this paper: $\mathrm{AP} \cdot{ }^{+}$, aminopyrine free radical cation; $\mathrm{CPZ} \cdot{ }^{+}$, chlorpromazine free radical cation; DMPO, 5,5-di-

The Journal of Clinical Investigation, Inc.

Volume 75, May 1985, 1618-1622 and horseradish peroxidase (5) and the prostaglandin-synthetasedependent production of the aminopyrine free radical cation $\left(\mathrm{AP}{ }^{+}\right.$) by a one-electron oxidation of aminopyrine (6). However, a two-electron oxidative pathway seems to generate free radicals in the tyrosinase-catalyzed oxidation of catecholamines (7).

Oxygen-containing free radicals such as the superoxide anion and the hydroxyl radical can be generated by several mechanisms in living organisms, including the oxidative microbicidal processes of phagocytic cells (8). Recently, neutrophils have been shown to produce genetic mutations in bacteria (9) and cytogenetic damage to the chromosomes of Chinese hamster ovary cells (10), apparently through the production of the hydroxyl radical. There is a significant correlation between the development of local cancers and the presence of infectious or noninfectious inflammatory processes (11). The possibility exists that neutrophils at inflammatory sites can directly cause mutations in surrounding cells, leading to the development of cancers. However, stimulated neutrophils also produce powerful oxidants through their myeloperoxidase system, which has the capacity to release hypochlorous acid into the surrounding medium $(12,13)$. Therefore, an alternative explanation for the association of inflammation and cancer is that neutrophils can oxidize potential carcinogens such as environmental pollutants, drugs, or even certain chemical compounds in foodstuffs (14) to highly toxic electrophilic free radical forms that might result in the neoplastic transformation of surrounding cells. This possibility is also consistent with the existing hypothesis that the ultimate metabolites initiating carcinogenesis are electrophiles (15). In addition, a similar mechanism might be involved in the toxicity of certain drugs that can be oxidized to free radical forms.

This study was undertaken to determine if the oxidants produced by neutrophils could generate potentially toxic free radical intermediates from certain foreign compounds. We report that hypochlorous acid, taurine chloramine, and the oxidants produced by stimulated neutrophils can convert chlorpromazine and aminopyrine to their free radical cation intermediates $\left(\mathrm{CPZ}^{+}{ }^{+}\right.$and $\left.\mathrm{AP}{ }^{+}\right)$and can also generate the phenyl radical $(\mathrm{Ph} \cdot)$ from phenylhydrazine.

\section{Methods}

Chemicals. Aminopyrine, chlorpromazine, phenylhydrazine, taurine, zymosan, sodium azide, potassium iodide, and catalase were obtained from Sigma Chemical Company, St. Louis, MO. Sodium hypochlorite, obtained from Aldrich Chemical Company, Milwaukee, WI, was used as a source of hypochlorous acid/hypochlorite ion $\left(\mathrm{HOCl} / \mathrm{OCl}^{-}\right)$solutions and was quantitated by its absorbance at $292 \mathrm{~nm}$. 5,5-dimethyl1-pyrroline N-oxide (DMPO), obtained from Aldrich Chemical Co., was purified over activated charcoal and kept frozen under nitrogen.

methyl-1-pyrroline N-oxide; ESR, electron spin resonance; HOCl/ $\mathrm{OCl}^{-}$, hypochlorous acid/hypochlorite ion; $\mathrm{Ph} \cdot$, phenyl radical. 
Phenylhydrazine was prepared in $0.2 \mathrm{M}$ acetic acid immediately before use to minimize autoxidation. Zymosan was opsonized by incubation of $5 \mathrm{mg}$ in $1 \mathrm{ml}$ of fresh human serum for $30 \mathrm{~min}$ at $37^{\circ} \mathrm{C}$ followed by washing three times in saline.

Cells. Heparinized peripheral blood from normal human volunteers was subjected to Hypaque-Ficoll density gradient centrifugation with the isolation of neutrophils as previously described (16). Red blood cells were removed by hypotonic lysis. Resulting preparations consisted of $98-99 \%$ neutrophils of $>96 \%$ viability (by Trypan blue dye exclusion) with little or no erythrocyte contamination.

Assays. The release of $\mathrm{HOCl} / \mathrm{OCl}^{-}$into the medium was quantitated using a modification of the chlorination of taurine method (17). This assay uses the ability of taurine to react with $\mathrm{HOCl} / \mathrm{OCl}^{-}$to form taurine chloramine, which is an oxidant more stable than $\mathrm{HOCl} / \mathrm{OCl}^{-}$ itself. The neutrophils $\left(5 \times 10^{6} / \mathrm{ml}\right)$ were incubated in phosphate buffered saline containing $5 \mathrm{mM}$ potassium chloride, $1 \mathrm{mM}$ calcium chloride, $1 \mathrm{mM}$ magnesium sulfate, and $5 \mathrm{mM}$ glucose at 7.4. In most instances, taurine was added before incubation and opsonized zymosan $(2 \mathrm{mg} / \mathrm{ml})$ was used as the neutrophil stimulant. Incubations were generally carried out at $22^{\circ} \mathrm{C}$. (Previous experiments in our laboratory have demonstrated optimal release of $\mathrm{HOCl} / \mathrm{OCl}^{-}$at $22^{\circ} \mathrm{C}$ with the use of opsonized zymosan as the stimulus.) In some experiments, sodium azide $\left(10^{-4} \mathrm{M}\right)$ was used to inhibit neutrophil myeloperoxidase. After incubation, the tubes were centrifuged and the supernatants were removed for quantitation of taurine chloramine. The latter was determined using the oxidation of iodide (added as $20 \mathrm{mM}$ potassium iodide) to iodine, which could be detected spectrophotometrically in an excess of $\mathrm{I}^{-}$as $\mathrm{I}_{3}^{-}$at $350 \mathrm{~nm}$. Catalase $(100 \mu \mathrm{g} / \mathrm{ml})$ was added before the $\mathrm{KI}$ in this assay to destroy any remaining hydrogen peroxide, which can (slowly) oxidize iodide to iodine. The data were expressed as nanomoles of $\mathrm{HOCl} / \mathrm{OCl}^{-}$produced by $5 \times 10^{6}$ neutrophils using a standard curve of sodium hypochlorite concentrations. Generation of stable oxidants produced by neutrophils, as recently described by Weiss et al. (18), was estimated in a similar manner except that taurine was not added to the incubation medium.

Generation of free radical intermediates from chlorpromazine, aminopyrine, and phenylhydrazine was studied using as oxidants sodium hypochlorite, taurine chloramine (which was produced by adding sodium hypochlorite to an excess of taurine) (17), and supernatants of stimulated neutrophils. The conditions were similar to those used in the assay for $\mathrm{HOCl} / \mathrm{OCl}^{-}$except that some of the experiments involving chlorpromazine were carried out at $37^{\circ} \mathrm{C}$ and using a reduced concentration $(5 \mathrm{mM})$ of taurine (preliminary experiments suggested that the higher taurine concentration might be somewhat inhibitory of $\mathrm{CPZ}^{+}{ }^{+}$generation). The free radical cations of chlorpromazine and aminopyrine are both relatively stable at $\mathrm{pH} 5.0$, and both absorb light in the visible range. Therefore, the $\mathrm{pH}$ of the solutions containing chlorpromazine and aminopyrine was first adjusted to $\mathrm{pH} 5.0$ using acetic acid. $\mathrm{CPZ} \cdot{ }^{+}$was determined spectrophotometrically at $526 \mathrm{~nm}$ using an extinction coefficient of $1.07 \times 10^{4} \mathrm{M}^{-1} \mathrm{~cm}^{-1}(19)$ and AP. + at $480 \mathrm{~nm}$ using an extinction coefficient of $2.5 \times 10^{3} \mathrm{M}^{-1} \mathrm{~cm}^{-1}(6)$.

Direct electron spin resonance (ESR) spectroscopy was used to confirm the presence of $\mathrm{CPZ} \cdot{ }^{+}$and $\mathrm{AP} \cdot{ }^{+}$, whereas production of $\mathrm{Ph}$. was quantitated using ESR spin trapping techniques $(20,21)$. The samples were transferred to a miniature quartz ESR flat cell that was placed in a dewar contained in the cavity of the ESR spectrometer (Varian E-109, Varian Associates, Inc., Palo Alto, CA). The ESR spectra were generated at room temperature. Spin-trapping of the phenyl radical by DMPO and subsequent evaluation of the DMPOphenyl adduct by ESR was used to detect generation of this radical from phenylhydrazine by the oxidants described above. These studies were carried out in PBS at pH 7.4 after adding $35 \mathrm{mM}$ DMPO and $10 \mathrm{mM}$ phenylhydrazine to solutions of sodium hypochlorite, taurine chloramine, or the neutrophil supernatants. These samples were kept frozen until they were analyzed by being thawed, transferred to the miniature flat cell, and investigated by ESR as described above. Spectra obtained in these studies were compared with known ESR spectra for $\mathrm{CPZ} \cdot{ }^{+}, \mathrm{AP} \cdot{ }^{+}$, and the DMPO-phenyl adduct $(5,6,22)$.

\section{Results}

Production of free radicals by sodium hypochlorite and taurine chloramine. Because stimulated neutrophils have been shown to release hypochlorous acid (17) and stable chloramines (18) into the surrounding medium, we first evaluated the capacity of these substances to oxidize foreign compounds to their free radical intermediates. Both sodium hypochlorite solutions and the stable chloramine, taurine chloramine, were able to produce the free radical intermediates from chlorpromazine, aminopyrine, and phenylhydrazine as detected using ESR and/or visible light spectroscopy. Fig. 1 shows the ESR spectra of $\mathrm{CPZ} \cdot{ }^{+}$and $\mathrm{AP} \cdot{ }^{+}$generated by taurine chloramine $(300 \mu \mathrm{M})$ and the DMPO-phenyl adduct generated by sodium hypochlorite $(400 \mu \mathrm{M})$. Similar spectra were obtained for $\mathrm{CPZ} .^{+}$and AP. ${ }^{+}$generated using $\mathrm{HOCl} / \mathrm{OCl}^{-}$and the DMPO-phenyl adduct generated using taurine chloramine (data not shown). The ESR spectra obtained for $\mathrm{CPZ} \cdot{ }^{+}$and $\mathrm{AP} \cdot{ }^{+}$were quite comparable to those described in previous studies $(5,6)$, and the ESR parameters of the DMPO-phenyl adduct agreed with the values in the literature (22).

The colored, relatively stable $\mathrm{CPZ} \cdot{ }^{+}$and $\mathrm{AP} \cdot{ }^{+}$radicals could be quantitated spectrophotometrically. However, whereas $\mathrm{CPZ}^{+}{ }^{+}$appeared immediately upon addition of the oxidants, AP. ${ }^{+}$required $\sim 60 \mathrm{~s}$ to develop. Both radicals began to disappear within several minutes. Fig. 2 shows the quantity of $\mathrm{CPZ}^{+}{ }^{+}$and $\mathrm{AP} \cdot{ }^{+}$produced by varying amounts of taurine chloramine. Note that detectable quantities of $\mathrm{CPZ} \cdot{ }^{+}$were produced by as little as $10-30 \mu \mathrm{M}$ taurine chloramine, an amount well within the capacity of neutrophils to produce (see below). In addition, Fig. $2 \mathrm{~A}$ also shows that there was a linear relationship between $\mathrm{CPZ}^{+}$and the quantity of taurine chloramine present. Quantitation of the amount of $\mathrm{CPZ} \cdot{ }^{+}$ and $\mathrm{AP} \cdot{ }^{+}$produced by $\mathrm{HOCl} / \mathrm{OCl}^{-}$was more difficult because

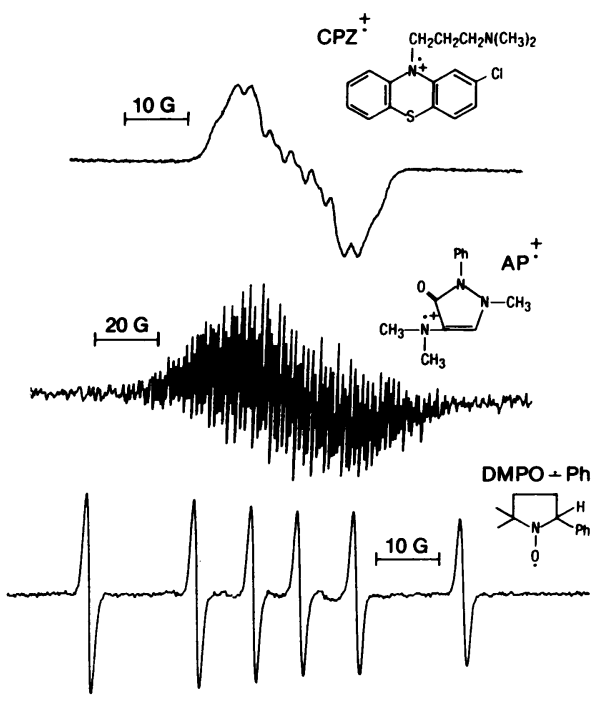

Figure 1. Electron spin resonance spectra of free radical intermediates generated by $\mathrm{HOCl} / \mathrm{OCl}^{-}$or taurine chloramine. Top, chlorpromazine free radical cation $\left(\mathrm{CPZ}^{\cdot}{ }^{+}\right)$produced by $300 \mu \mathrm{M} \mathrm{NaOCl}$ plus $20 \mathrm{mM}$ taurine. Middle, Aminopyrine free radical cation (AP. ${ }^{+}$) produced by $300 \mu \mathrm{M} \mathrm{NaOCl}$ plus $20 \mathrm{mM}$ taurine. Bottom, spin adduct of the phenyl radical ( $\mathrm{Ph} \cdot$ ) produced by $400 \mu \mathrm{M} \mathrm{NaOCl}$ in the presence of the spin trap, DMPO $(35 \mathrm{mM})$. Structures of the free radicals are shown to the right of their respective spectra. 

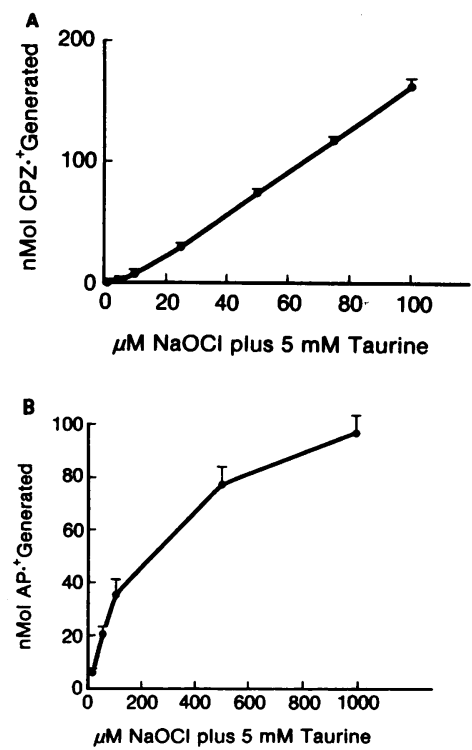

Figure 2. (A) Generation of the chlorpromazine free radical cation $\left(\mathrm{CPZ}^{+}\right)$by taurine chloramine. Chlorpromazine $(10 \mathrm{mM})$ was added to varying concentrations of $\mathrm{NaOCl}$ in the presence of $5 \mathrm{mM}$ taurine at pH 5.0. Optical density was determined at $526 \mathrm{~nm}$ immediately after addition of chlorpromazine. $(B)$ Generation of the aminopyrine free radical cation $\left(\mathrm{AP}{ }^{+}\right)$by taurine chloramine. Aminopyrine ( 10 $\mathrm{mM}$ ) was added to varying concentrations of $\mathrm{NaOCl}$ in the presence of $5 \mathrm{mM}$ taurine at $\mathrm{pH}$ 5.0. Optical density was determined at $480 \mathrm{~nm}$ when the color reached its maximal intensity.

the radicals produced seemed to decay more rapidly than when taurine chloramine was used as the oxidant.

Production of free radicals by neutrophil-derived oxidants. Neutrophils were stimulated with opsonized zymosan in the presence or absence of taurine and the supernatants were tested to determine the amount of $\mathrm{HOCl} / \mathrm{OCl}^{-}$that had been produced and their ability to generate the free radical intermediates. Table I shows that the stimulated neutrophils released into the medium $88.3 \pm 23.6 \mathrm{nMol}$ of $\mathrm{HOCl} / \mathrm{OCl}^{-}$per $5 \times 10^{6}$ cells. As an estimate of the amount of stable oxidant produced, $5 \times 10^{6}$ stimulated neutrophils produced an equivalent of $12.3 \pm 0.8 \mathrm{nmol}$ of $\mathrm{HOCl} / \mathrm{OCl}^{-}$in the absence of taurine. Significant amounts of $\mathrm{CPZ} \cdot{ }^{+}$and $\mathrm{AP} \cdot{ }^{+}$were detected spectrophotometrically when $10 \mathrm{mM}$ of either chlorpromazine or aminopyrine were introduced into these supernatants after adjusting the pH to 5.0 to increase the stability of the radicals. These data are shown in Table II for chlorpromazine and Table III for aminopyrine. Note that reduction of the $\mathrm{pH}$ was done to increase stability of the radicals so they could be measured; generation of these species apparently occurs at

Table I. Production of Hypochlorous Acid by Neutrophils

\begin{tabular}{|c|c|}
\hline Additions & $\begin{array}{l}\mathrm{nmol} \mathrm{HOCl} / \mathrm{OCl}^{-} \text {per } 5 \times 10^{\circ} \\
\text { cells in } 1.0-\mathrm{ml} \text { cultures }\end{array}$ \\
\hline Cells alone & $5.8 \pm 1.3$ \\
\hline Cells plus taurine* & $7.0 \pm 0.9$ \\
\hline Cells plus op zy & $12.3 \pm 0.7$ \\
\hline Cells plus taurine plus op zy & $88.3 \pm 23.6$ \\
\hline Cells plus taurine plus op zy plus azide§ & $8.7 \pm 0.6$ \\
\hline
\end{tabular}

* Taurine concentration was $20 \mathrm{mM}$.

‡ op zy, opsonized zymosan $(2 \mathrm{mg} / \mathrm{ml})$.

\$ Azide concentration, $0.1 \mathrm{mM}$.

Data represent mean $\pm \mathrm{SE}$ for three experiments carried out at $22^{\circ} \mathrm{C}$ and a 2-h incubation. Statistical significance (unpaired $t$ test): cells alone vs. cells plus op zy, $P<0.05$; cells plus taurine vs. cells plus taurine plus op zy, $P<0.05$.
Table II. Generation of CPZ $\cdot{ }^{+}$by Neutrophil Supernatants as Determined Spectrophotometrically

\begin{tabular}{|c|c|}
\hline Additions & $\begin{array}{l}\text { nmol CPZ. }{ }^{+} \text {per } 5 \times 10^{\circ} \\
\text { cells in } 1.0-\mathrm{ml} \text { cultures }\end{array}$ \\
\hline \multicolumn{2}{|l|}{ Part A. $22^{\circ} \mathrm{C}, 2$-h incubation } \\
\hline Cells alone & $0 \pm 0$ \\
\hline Cells plus taurine* & $0 \pm 0$ \\
\hline Cells plus op zy $\ddagger$ & $2.5 \pm 0.7$ \\
\hline Cells plus taurine plus op zy & $68.1 \pm 9.9$ \\
\hline Cells plus taurine plus op zy plus azide $\S$ & $0.1 \pm 0.1$ \\
\hline \multicolumn{2}{|l|}{ Part B. $37^{\circ} \mathrm{C}, 2-\mathrm{h}$ incubation } \\
\hline Cells alone & $1.5 \pm 0.8$ \\
\hline Cells plus taurine & $1.9 \pm 0.5$ \\
\hline Cells plus op zy & $10.4 \pm 2.4$ \\
\hline Cells plus taurine plus op zy & $80.7 \pm 13.3$ \\
\hline Cells plus taurine plus op zy plus azide & $2.1 \pm 0.5$ \\
\hline \multicolumn{2}{|l|}{ Part C. $37^{\circ} \mathrm{C}$, varying incubation periods } \\
\hline Cells plus taurine, $120 \mathrm{~min}$ & $1.4 \pm 0.8$ \\
\hline Cells plus taurine plus op $\mathrm{zy}, 5 \mathrm{~min}$ & $19.2 \pm 4.3$ \\
\hline Cells plus taurine plus op zy, $20 \mathrm{~min}$ & $41.6 \pm 2.8$ \\
\hline Cells plus taurine plus op zy, $60 \mathrm{~min}$ & $44.1 \pm 7.6$ \\
\hline Cells plus taurine plus op $\mathrm{zy}, 120 \mathrm{~min}$ & $78.8 \pm 18.6$ \\
\hline
\end{tabular}

* Taurine concentration was $20 \mathrm{mM}$ for experiments at $22^{\circ} \mathrm{C}, 5 \mathrm{mM}$ for experiments at $37^{\circ} \mathrm{C}$.

‡ op zy, opsonized zymosan $(2 \mathrm{mg} / \mathrm{ml})$.

$\S$ Azide concentration was $0.1 \mathrm{mM}$.

Data represent mean \pm SE for three experiments (parts $A$ and $C$ ) or four experiments (part B). Statistical significance (unpaired $t$ test): Part A, cells vs. cells plus op zy, $P<0.05$; cells plus taurine vs. cells plus taurine plus op zy, $P<0.01$; part $\mathrm{B}$, cells vs. cells plus op zy, $P$ $<0.02$; cells plus taurine vs. cells plus taurine plus op zy, $P<0.01$.

physiological pH's $(5,6)$. Table II also demonstrates the production of $\mathrm{CPZ} \cdot{ }^{+}$by the supernatants of neutrophils stimulated $\left(\right.$ at $37^{\circ} \mathrm{C}$ ) at various times beforehand. The ability to generate this radical began at or before $5 \mathrm{~min}$ of incubation and increased over the $2-h$ incubation period. Generation of $\mathrm{Ph}$ - from phenylhydrazine was detected by ESR-spin trapping

Table III. Generation of AP. ${ }^{+}$by Neutrophil Supernatants as Determined Spectrophotometrically

\begin{tabular}{ll}
\hline Additions & $\begin{array}{l}\text { nmol AP. }{ }^{+} \text {per } 5 \times 10^{6} \\
\text { cells in } 1.0 \text {-ml cultures }\end{array}$ \\
\hline Cells alone & $0.2 \pm 0.1$ \\
Cells plus taurine* & $0.7 \pm 0.1$ \\
Cells plus op zył & $0.8 \pm 0.4$ \\
Cells plus taurine plus op zy & $9.5 \pm 0.2$ \\
Cells plus taurine plus op zy plus azide§ & $0.5 \pm 0.1$
\end{tabular}

* Taurine concentration was $20 \mathrm{mM}$. ‡ op zy, opsonized zymosan $(2 \mathrm{mg} / \mathrm{ml})$. $\S$ Azide concentration was $0.1 \mathrm{mM}$. Data represent mean $\pm \mathrm{SE}$ for three experiments carried out at $22^{\circ} \mathrm{C}$ and a 2-h incubation. Statistical significance (unpaired $t$ test): cells alone vs. cells plus op zy, NS; cells plus taurine vs. cells plus taurine plus op zy, $P<0.001$. 
at $\mathrm{pH} 7.4$ in the neutrophil supernatants when $35 \mathrm{mM}$ DMPO and $10 \mathrm{mM}$ phenylhydrazine were added (Table IV). Sodium azide (an inhibitor of myeloperoxidase) suppressed production of hypochlorous acid and the ability of the supernatants to generate all three radicals. Production of the free radicals in each case was also reduced in the absence of taurine.

\section{Discussion}

This study shows that the type and quantity of oxidants produced by stimulated human neutrophils can generate free radical intermediates from chlorpromazine, aminopyrine, and phenylhydrazine. As an integral part of their microbicidal mechanisms, stimulated neutrophils remove from the medium relatively large quantities of oxygen, which are sequentially converted to the superoxide anion radical, hydrogen peroxide, and $\mathrm{HOCl} / \mathrm{OCl}^{-}$(23). In contrast to most other peroxidases, myeloperoxidase converts hydrogen peroxide and chloride ion to a strong oxidant that can diffuse away from the enzyme complex (and into the medium surrounding the cell) as $\mathrm{HOCl}$ / $\mathrm{OCl}^{-}$(13). The latter is an effective microbicidal agent that readily oxidizes many biologic molecules and can react with amino groups to form chloramines of varying stability (24). Since in the presence of neutrophils, $\mathrm{HOCl} / \mathrm{OCl}^{-}$is a shortlived species, we found it necessary to trap this compound as taurine chloramine, a molecule that retains significant oxidizing capacity, to show most clearly the ability of neutrophil supernatants to generate these free radical intermediates. Neutrophils also seem to produce some of their oxidants in a stable form, probably representing chloramines (18). With chlorpromazine and phenylhydrazine, some activity of the supernatants was present in the absence of taurine, presumably due to the presence of these stable chloramines generated by the stimulated cells. Alternatively, the combination of hydrogen peroxide and myeloperoxidase released from stimulated neutrophils might also have been capable of generating these free radical intermediates. In addition, supernatants from neutrophils triggered in the presence of azide were still able to produce relatively large amounts of the DMPO-phenyl adduct. One possible explanation for this observation could be that hydrogen peroxide might accumulate in the supernatants under these conditions and could oxidize phenylhydrazine to $\mathrm{Ph}$ - in the presence of

Table IV. Generation of $\mathrm{Ph} \cdot$ from Phenylhydrazine by Neutrophil Supernatants as Measured by ESR-Spin-Trapping

\begin{tabular}{lc}
\hline Additions & $\begin{array}{l}\text { Concentration of DMPO-Ph. } \\
\text { in arbitrary units }\end{array}$ \\
\hline Cells alone & $4.0 \pm 1.0$ \\
Cells plus taurine* & $8.8 \pm 2.1$ \\
Cells plus op zy & $18.7 \pm 1.2$ \\
Cells plus taurine plus op zy & $27.7 \pm 5.2$ \\
Cells plus taurine plus op zy plus azide & $14.7 \pm 3.4$
\end{tabular}

* Taurine concentration was $20 \mathrm{mM}$.

$\ddagger$ op zy, opsonized zymosan $(2 \mathrm{mg} / \mathrm{ml})$.

$\S$ Azide concentration was $0.1 \mathrm{mM}$.

Data represent mean $\pm \mathrm{SE}$ for three experiments using the supernatants generated from $5 \times 10^{6} \mathrm{cells} / \mathrm{ml}$ at $22^{\circ} \mathrm{C}$ and a 2-h incubation. Statistical significance (unpaired $t$ test): cells alone vs. cells plus op $\mathrm{zy}, P<0.001$; cells plus taurine vs. cells plus taurine plus op zy, $P<0.05$. certain metal ions, particularly ferrous iron. In summary, the results of these studies demonstrate that $\mathrm{HOCl} / \mathrm{OCl}^{-}$solutions, taurine chloramine, and neutrophil oxidants in the form of either taurine chloramine or in some cases, the stable oxidants, can generate free radical intermediates from structurally diverse foreign compounds.

A wide variety of compounds can be converted to free radical intermediates by a number of oxidizing conditions, including horseradish peroxidase and hydrogen peroxide, prostaglandin synthetase/arachidonic acid, ceruloplasmin, and the microsomal cytochrome P-450 system (3). The types of oxidants produced by neutrophils also seem to be capable of this conversion. The linear relationship that we observed between the amount of $\mathrm{CPZ} \cdot{ }^{+}$generated and the quantity of taurine chloramine added as expressed arithmetically (Fig. 2) suggests that a two-electron oxidation process may have been involved in this process. One possibility is that $\mathrm{CPZ} \cdot{ }^{+}$and $\mathrm{AP}^{+}$ produced by $\mathrm{HOCl} / \mathrm{OCl}^{-}$or taurine chloramine could have been generated via a back reaction between the two-electron oxidation intermediates and their respective parent compounds. Under other conditions, $\mathrm{Ph}$ - seems to be produced from phenylhydrazine by decomposition of phenyl diazene, the twoelectron oxidation intermediate $(20,25)$, and this mechanism could be involved in the production of this species by the neutrophil-derived oxidants.

The three compounds used in this study all have significant in vivo toxicity under the appropriate conditions. Whereas chlorpromazine is a safe and effective drug in most instances, it does exhibit a variety of toxic effects. Both chlorpromazine and aminopyrine can produce neutropenia when used therapeutically in humans $(26,27)$. This side effect has limited the usefulness of aminopyrine as an antipyretic. The formation of $\mathrm{CPZ} \cdot{ }^{+}$has been suggested as a cause of the toxic side effects of chlorpromazine therapy by the interaction of this radical with endogenous cellular reductants (28). The hydrazines are an interesting group of compounds that have toxic and carcinogenic properties $(25,29)$. Covalent binding to the heme moiety of hemoglobin by $\mathrm{Ph}$ - generated from phenylhydrazine has been implicated in the toxicity of this compound for erythrocytes (25). Under the proper conditions, neutrophils might be able to oxidize other chemical compounds to their free radical intermediates, and it is possible that this mechanism could be involved in the toxicity of some of these compounds.

Local cancers often occur at sites of infectious or noninfectious inflammatory processes. Examples are squamous cell carcinomas associated with the fistulas from chronic osteomyelitis (30), bladder carcinoma in schistosomiasis (31), testicular carcinoma in mumps orchitis (32), and gastrointestinal carcinoma in inflammatory bowel disease (33). A number of plausible explanations for this association between inflammation and cancer are possible, including an increased rate of epithelial turnover in the inflamed tissue, direct effects on cellular DNA by a viral agent causing the inflammation, and chromosomal damage caused by oxygen-containing free radicals produced by the stimulated inflammatory cells. There is a reasonable likelihood that many tissues in the human body are frequently exposed to a wide variety of compounds that can be oxidized to potentially toxic free radical intermediates. Sources of such compounds may be exogenous, as in the cases of industrial pollutants, drugs, and naturally occurring chemicals in foods; or may be endogenous, as with mediators such as catecholamines. While some of the free radical intermediates may be 
stable enough to travel away from the site of generation, most would probably act locally. Therefore, conversion of chemical compounds to toxic-free radical intermediates by stimulated phagocytic cells in a localized inflammatory process could be an additional explanation for the association between inflammation and cancer.

If stimulated neutrophils can indeed oxidize various chemical compounds to their electrophilic free radical intermediates in vivo, this process may represent a new pathway for the metabolism of these compounds. This pathway could be important in the toxicity of certain drugs and in the carcinogenic potential of other chemical compounds.

\section{Acknowledgments}

The authors thank Miss Victoria Gollish for her excellent editorial assistance.

This work was supported by the Veterans Administration Medical Research Service and grants GM-29035 and RR-01008 from the National Institutes of Health.

\section{References}

1. Docampo, R., and S. N. J. Moreno. 1984. Free radical metabolites in the mode of action of chemotherapeutic agents and phagocytic cells on Trypanosoma cruzi. Rev. Infect. Dis. 6:223-228.

2. Trush, M. A., E. G. Mimwaugh, and T. E. Gram. 1982. Activation of pharmacologic agents to radical intermediates. Implications for the role of free radicals in drug action and toxicity. Biochem. Pharmacol. 47:412-426.

3. Mason, R. P. 1979. Free radical metabolites of foreign compounds and their toxicological significance. In Reviews in Biochemical Toxicology, Vol. 1. E. Hodgson, J. R. Bend, and R. M. Philpot, editors. Elsevier-North Holland, New York. 151-200.

4. Ts'o, P. O. P., W. J. Caspary, and R. J. Lorentzen. 1977. The involvement of free radicals in chemical carcinogenesis. In Free Radicals in Biology, Vol. III. W. A. Pryor, editor. Academic Press, New York. 268-275.

5. Piette, L. H., G. Bulow, and I. Yamazaki. 1964. Electronparamagnetic-resonance studies of the chlorpromazine free radical formed during enzymatic oxidation by peroxidase-hydrogen peroxide. Biochim. Biophys. Acta 88:120-129.

6. Lasker, J. M., K. Sivarajah, R. P. Mason, B. Kalanaraman, M. B. Abou-Donia, and T. E. Eling. 1981. A free radical mechanism of prostaglandin synthetase-dependent aminopyrine demethylation. $J$. Biol. Chem. 256:7764-7767.

7. Mason, H. S. 1955. Comparative biochemistry of the phenolase complex. Adv. Enzymol. Relat. Areas Mol. Biol. 16:105-184.

8. Leibovitz, B. E., and B. V. Siegel. 1980. Aspects of free radical reactions in biological systems: aging. J. Gerontol. 35:45-56.

9. Weitzman, S. A., and T. P. Stossel. 1981. Mutation caused by human phagocytes. Science (Wash. DC). 212:546-547.

10. Weitberg, A. B., S. A. Weitzman, M. Destrempes, S. A. Latt, and T. P. Stossel. 1983. Stimulated human phagocytes produce cytogenetic changes in cultured mammalian cells. N. Engl. J. Med. 308: 21-30.

11. Templeton, A. C. 1975. Acquired diseases, Chapter 4. In Persons at High Risk of Cancer. An Approach to Cancer Etiology and Control. J. F. Fraumeni, Jr., editor. Academic Press, New York. 6984.

12. Babior, B. M. 1984. The respiratory burst of phagocytes. $J$. Clin. Invest. 73:599-601.

13. Harrison, J. E., and J. Schultz. 1976. Studies on the chlorinating activity of myeloperoxidase. J. Biol. Chem. 251:1371-1374.

14. Ames, B. N. 1983. Dietary carcinogens and anticarcinogens.
Oxygen radicals and degenerative diseases. Science (Wash. DC). 221: 1256-1263.

15. Miller, E. C., and J. A. Miller. 1981. Searches for ultimate chemical carcinogens and their reactions with cellular macromolecules. Cancer (Phila.). 10:2327-2345.

16. Sohnle, P. G., and C. Collins-Lech. 1978. Cell-mediated immunity to Pityrosporum orbiculare in tinea versicolor. J. Clin. Invest. 62:45-53.

17. Weiss, S. J., R. Klein, A. Slivka, and M. Wei. 1982. Chlorination of taurine by human neutrophils: evidence for hypochlorous acid generation. J. Clin. Invest. 70:598-607.

18. Weiss, S. J., M. B. Lampert, and S. T. Test. 1983. Long-lived oxidants generated by human neutrophils: characterization and bioactivity. Science (Wash. DC). 222:625-626.

19. Pelizzetti, E., D. Meisel, W. A. Mulac, and P. Neta. 1979. On the electron transfer from ascorbic acid to various phenothiazine radicals. J. Am. Chem. Soc. 101:6954-6959.

20. Kalyanaraman, B. 1982. Detection of toxic free radicals in biology and medicine. In Reviews in Biochemical Toxicology. Vol. 4. C. E. Hodgson, J. R. Bend, and R. M. Philpot, editors. Elsevier/North Holland, New York. 73-139.

21. Janzen, E. G. 1980. A critical review of spin-trapping in biological systems. In Free Radicals in Biology. Vol. 4. W. A. Pryor, editor. Academic Press, New York. 115-154.

22. Augusto, O., K. L. Kunze, and P. R. Ortiz de Montellano. 1982. N-phenylprotoporphyrin IX formation in the hemoglobin-phenylhydrazine reaction: evidence for a protein-stabilized iron-phenyl intermediate. J. Biol. Chem. 257:6231-6241.

23. Root, R. K., and M. S. Cohen. 1981. The microbicidal mechanisms of human neutrophils and eosinophils. Rev. Infect. Dis. 3:565-598.

24. Thomas, E. L. 1979. Myeloperoxidase, hydrogen peroxide, chloride antimicrobial system: nitrogen-chlorine derivatives of bacterial components in bactericidal action against Escherichia coli. Infect. Immun. 23:522-531.

25. Maloney, S. J., and R. A. Prough. 1984. Biochemical toxicology of hydrazines. In Reviews in Biochemical Toxicology. Vol. 5. C. E. Hodgson, S. R. Bend, and R. M. Philpot, editors. Elsevier/North Holland, Amsterdam. 313-348.

26. Baldessarini, R. J. 1980. Drugs and the treatment of psychiatric disorders. In The Pharmacological Basis of Therapeutics. 6th Edition. A. G. Gilman, L. S. Goodman, and A. Gilman, editors. MacMillan Publishing Co., Inc., New York. 391-447.

27. Flower, R. J., S. Moncada, and J. R. Vane. 1980. Analgesicantipyretics and anti-inflammatory agents: drugs employed in the treatment of gout. In The Pharmacological Basis of Therapeutics. 6th Edition. A. G. Gilman, L. S. Goodman, and A. Gilman, editors. MacMillan Publishing Co., Inc., New York. 701.

28. Mayausky, J. S., H. Y. Cheng, P. H. Sackett, and R. L. McCreery. 1982. Spectroelectrochemical examination of the reactions of chlorpromazine cation radical with physiological macromolecules. In Advances in Chemistry Series, No. 201. American Chemical Society. 443-456.

29. Toth, B. 1975. Synthetic and naturally-occurring hydrazines as possible cancer causative agents. Cancer Res. 35:3693-3697.

30. Manale, B. L., and T. D. Brower. 1973. The significance of bacterial flora in carcinoma in chronic osteomyelitis. Surg. Gynecol. Obstet. 136:63-64.

31. Kuntz, R. E., A. M. Cheever, and B. J. Myers. 1972. Proliferative epithelial lesions of the urinary bladder of non-human primates infected with Schistosoma hematobium. J. Natl. Cancer Inst. 68:223235.

32. Gilbert, J. B. 1944. Tumors of the testis following mumps orchitis. J. Urol. 51:296-300.

33. Saeed, W., S. Kim, and B. H. Burch. 1974. Development of carcinoma in regional enteritis. Arch. Surg. 108:376-379. 